\title{
GERENCIAMENTO DE INSTITUIÇÕES DE ENSINO COMO ORGANIZAÇÃO: UM ENFOQUE NA QUALIDADE
}

\author{
EDUCATIONAL INSTITUTIONS MANAGEMENT AS ORGANIZATION: QUALITY FOCUS \\ GESTIÓN DE INSTITUCIONES EDUCATIVAS COMO ORGANIZACIÓN: ENFOQUE DE \\ CALIDAD
}

Ricardo Correa de Almeida ${ }^{1}$

\begin{abstract}
RESUMO
Este artigo discute a utilização do PDCA na gestão de instituições de ensino com foco no nível superior. Para isso, ampara-se na norma gestão da qualidade ISO 21001:2018, que adota termos específicos do setor de educação em relação. Tanto a norma ISO 9001:2015 como a ISO 21001:2018 utilizam o ciclo PDCA adaptado ao seu sistema de gestão, inclusive nas instituições educacionais. Essa integração visa garantir a melhoria contínua na organização das instituições de ensino e definir como as etapas do ciclo podem auxiliar na resolução desses problemas auxiliando o sistema de gestão. Ao final constatamos que os dois padrões usam a mesma estrutura de alto nível, sendo o PDCA uma das ferramentas que podem ser aplicadas na racionalização dos processos de gestão, principalmente, no planejamento de ações e tomada de decisões. Demonstrou-se que, quando se aplica o ciclo PDCA, há um aproveitamento dos processos com redução de custos e aumento da produtividade.
\end{abstract}

PALAVRAS-CHAVE: Gestão educacional. PDCA. ISO 21001:2018. ISO 9001:2015.

\begin{abstract}
This article discusses the PDCA use in educational management institutions with focus on the university. It is based on the ISO 21001:2018 quality management standard, which adopts terms specific for the education sector. Both ISO 9001:2015 and ISO 21001:2018 use the PDCA cycle adapted to their management system, ${ }^{2}$ including in educational institutions. This integration aims to ensure continuous improvement for educational institutions and define how the stages of the cycle can solve these problems by assisting the ${ }^{3}$ management system. At the end, we find that both standards use the same high-level structure, PDCA is one of the tools that can be applied in the rationalization of management processes, mainly in action planning and decision. It has been demonstrated that, when the PDCA cycle is applied, the processes and cost reduction are improved and productivity increased.
\end{abstract}

KEYWORDS: Educational management. PDCA. ISO 21001:2018. ISO 9001:2015

\section{RESUMEN}

En este artículo se analiza el uso del PDCA en la gestión de las instituciones educativas, centrándose en el nivel superior. Se basa en el estándar de gestión de calidad ISO 21001:2018, que adopta términos específicos del sector de la educación en relación con esto. Tanto la ISO 9001:2015 como la ISO 21001:2018 utilizan el ciclo PDCA adaptado a su sistema de gestión, incluso en las instituciones educativas.

Esta integración tiene por objeto garantizar el mejoramiento continuo de la organización de las instituciones educativas y definir la forma en que las etapas del ciclo pueden ayudar a resolver estos problemas mediante la asistencia al sistema de gestión. Al final, encontramos que los dos estándares utilizan la misma estructura de alto nivel, siendo el PDCA una de las herramientas que puede aplicarse en la racionalización de los procesos de gestión, principalmente en la planificación de acciones y la toma de decisiones. Se ha demostrado que, cuando se aplica el ciclo PDCA, se produce una explotación de los procesos con reducción de costos y aumento de la productividad.

\footnotetext{
${ }^{1}$ Doutor em Educação (PUC SP). Docente do Mestrado em Educação da Univas.
} 
PALABRAS CLAVE: Gestión educativa. PDCA. ISO 21001:2018. ISO 9001:2015.

\section{CONSIDERAÇÕES INICIAIS}

A escola como organização, no Brasil, tem seu marco na década de 1990 no contexto de um movimento denominado "Reforma" que ocorreu na gestão do Governo Fernando Henrique Cardoso, entretanto, no mundo desenvolvido seu marco remonta à década de 1980. Segundo Licínio Lima (2011), o setor público foi tomado por ideais assentados na ideologia do mercado, em coerência às tendências neoliberais especialmente presentes a partir da década de oitenta, por meio das chamadas "Reformas". Tais programas de reforma se amparam na iniciativa privada como modelo, forçando a administração pública a uma gestão racional, denominada gerencial, perspectivando-a como um serviço dirigido aos cidadãos, tomados como clientes e consumidores [...] políticas educativas de modernização e de reforma integram frequentemente pressupostos, adotam orientações e consagram soluções do tipo neotayloriano (LIMA, 2011, p. 135-136).

A reforma no Brasil foi lastreada em quatro pilares, interdependentes, quais sejam: a delimitação do tamanho do Estado, a redefinição do papel regulador do Estado, a recuperação da governança e o aumento da governabilidade (Bresser-Pereira, 1997). Ela estabeleceu as diretrizes do que chamou-se de Reforma do Estado, buscando a adequação da administração pública nacional a critérios do que se acredita ser a moderna administração gerencial, segundo 0 Banco Mundial foi liderada pelo então ministro do extinto Ministério da Administração Federal e Reforma do Estado (MARE), Luís Carlos Bresser Pereira.

0 aspecto regulatório da Reforma diz respeito à maior ou menor intervenção governamental no mercado, por meio de mudanças no processo de governança, via racionalidade técnica. Nas instituições públicas, inclusive as educacionais, relaciona-se aos aspectos financeiros, estratégico e administrativo visando a redução de custos e 0 aumento da produtividade. Nesse contexto se insere a tendência de tratar a escola como organização educativa, tratada como objeto de estudo por diversos autores, dentre eles Licínio Lima (2011). Para esse autor, a organização educativa constitui um universo aberto de grande complexidade, heterogeneidade e diversidade. Lima (2011) explica que, nessa visão deve-se articular Estado, sistemas político e econômico, escola, sala de aula, comunidade escolar e atores da escola, de forma que possa se instalar o diálogo, as discussões, o estudo e o encontro de perspectivas, sem expressões prescritivas ou restritivas, mas, ao contrário, adaptáveis à variedade de 
circunstâncias e realidades. Trata-se de ações inovadoras, criativas com combinação de teorias, métodos e ferramentas de aprendizagem singulares, coerentes com as diversas realidades de cada organização educativa que tem em vista melhorar a qualidade dos serviços educacionais prestados.

A abordagem de Lima (2011) vai ao encontro do impasse em que se encontra a escola, como organização, quanto às novas perspectivas que se vislumbram com a mudança do centro de gravidade do conhecimento para o atingimento de resultados. Tradicionalmente, com uma estrutura burocrática, hierarquizada, sustentada em modelos normativos e prescritivos, as instituições de ensino se veem hoje, com muita dificuldade de se adaptar aos novos modelos de uma sociedade que exige cada vez mais participação, autonomia e inovação. Isso é ainda mais relevante no caso da instituição pública, controlada centralmente pelo Estado, em que a diversidade de interesses e de ideologias e grupos antagônicos tornam mais difíceis a proposta de objetivos consistentes e partilhados por todos, "seja por falta de espaço de intervenção, seja mesmo devido aos efeitos de socialização para a conformidade, indispensável e funcional num sistema centralizado" (LIMA, 2007, p. 20).

A organização educativa se insere neste contexto e, na perspectiva de Lima (2011), todo e qualquer profissional desempenha um conjunto de funções, imbricadas entre si, para cujo desempenho no exercício de quaisquer funções são necessários conhecimentos, habilidades e atitudes específicos e sinergicamente articulados entre si. Dessa forma, não é diferente para 0 profissional que ocupa outros cargos de gestão em escolas ou em outras áreas da educação, inclusive a sala de aula (CÁRIA, OLIVEIRA E CUNHA, 2015). A adoção de propostas da racionalidade econômica no âmbito educacional se dá sob o manto de modernização do sistema educativo, toma por referência a busca pela otimização, eficácia e eficiência desse sistema para as políticas públicas.

O ponto de apoio da reforma gerencial, Cabral Neto e Castro (2011, p. 748) defendem que "é a busca da eficiência, pela redução e controle dos gastos públicos, pela demanda de melhor qualidade dos serviços públicos, pela descentralização administrativa, concedendo maior autonomia às agências e departamentos". Sobre as políticas públicas de gestão com foco na eficiência, os autores frisam a preocupação, portanto, com o produto em detrimento dos processos.

Recentemente a Organização Internacional de Padronização (ISO) publicou um novo padrão de Sistemas de Gerenciamento para Organizações Educacionais (SGOE). Trata-se da ISO 21001:2018, a qual descreve os requisitos para organizações educacionais com foco no 
aprimoramento da gestão nas organizações educacionais e seus respectivos serviços e produtos educacionais, sendo o PDCA uma das ferramentas que podem ser aplicadas na racionalização dos processos de gestão, principalmente, no planejamento das ações para tomada de decisões.

Este artigo tem como objetivo apontar as vantagens da adoção do PDCA (Plan, Do, Check, Act) na gestão de instituições de ensino, utilizando-se uma análise qualitativa para avaliar se o novo padrão é mais adequado para organizações educacionais. Parte-se da hipótese de que o PDCA é um método gerencial de planejamento de ações fortificando o embasamento para tomada de decisões, capaz de contribuir para o aprimoramento da gestão de instituições de ensino, especificamente do ensino superior, tendo em vista garantir o cumprimento das metas e a melhoria dos resultados da organização educativa ao comparar o SGOE 21001:2018 e o SGQ ISO 9001: 2015.

O texto ressalta a importância de se trabalhar o Ciclo PDCA integrado com um Sistema de Gestão da Qualidade - SGQ ISO 9001: 2015 - e um Sistema de Gerenciamento para Organizações Educacionais - SGOE 21001:2018, visto que estas duas normas adotam em seu conteúdo o uso do PDCA de forma adaptada a sua necessidade.

\section{EM BUSCA DA QUALIDADE}

O ciclo PDCA, foi desenvolvido por Walter A. Shewart na década de 20, mas começou a ser implementado como ciclo de Deming em 1950, por ter sido extensamente propagado por este. É uma ferramenta simples que tem como objetivo o controle do processo, possibilitando seu uso de forma contínua para o gerenciamento das atividades gerenciais. Visa monitorar as necessidades buscando obter resultados eficazes e ordenação nas atividades de uma organização, sendo também considerado como um eficiente modo de identificar melhorias no processo, padronizando as informações do controle da qualidade, evitando erros lógicos nas análises, simplificando as informações para tomada de ações, podendo também ser usado para facilitar o direcionamento para a busca constante da melhoria contínua. A melhoria contínua é, atualmente um dos pontos principais e estratégicos dos sistemas de gestão da qualidade nas empresas. A revolução da qualidade ocorrida no Japão a partir da década de 50 teve como uma das bases estratégicas o melhoramento da qualidade em um ritmo contínuo e revolucionário nos processos. 
A Organização Internacional de Padronização - ISO - sendo uma das mais antigas e mais experientes no campo da padronização da indústria, segue como uma referência global de padronização para organizações, empresas, formuladores de políticas, e apoio a vários regulamentos em todo o mundo. A revisão das normas ISO 9000 reforçou a importância da melhoria contínua nos processos da empresa, exigindo registros que comprovem que a empresa teve, de fato, melhoria em seu processo produtivo e organizacional. Esta comprovação deve-se ocorrer de forma documental, registrando-se toda a situação inicial e após a implantação da melhoria, sendo requisitada em futuras auditorias pelas empresas de certificação.

Um de seus padrões mais recentes publicados é a ISO 21001:2018 - Sistemas de Gerenciamento para Organizações Educacionais (SGOE), que tem como foco as organizações educacionais e seus respectivos serviços e produtos, bem como a melhoria e / ou aprimoramento de serviços e produtos educacionais. Substancialmente, a ISO 21001 é uma norma baseada na ISO 9001 com requisitos específicos para Organizações Educacionais. Esta norma está cancelando e substituindo a ABNT NBR 15419:2006 (Sistemas de gestão da qualidade - Diretrizes para aplicação da ABNT NBR ISO 9001:2000 nas organizações educacionais). Através da utilização da "Estrutura de Alto Nível", significa que o SGOE tem a mesma estrutura que a ISO 9001: 2015 e outros padrões revisados subsequentes, mas com conteúdo alinhado especificamente para o setor. A Estrutura de Alto Nível é essencial para as organizações que podem escolher por operar com um único sistema de gerenciamento, conhecido como Sistema de Gerenciamento Integrado, que combina dois ou mais padrões de sistema de gerenciamento, facilitando para as organizações adotarem outros padrões ISO que possuem a mesma estrutura.

A diferença da ISO 21001 de outras normas existentes do sistema de gerenciamento da ISO, são as orientações para o uso dos anexos ( $A$ à $G$ ), que fornecem orientações $e$ informações consideráveis em relação aos requisitos da ISO 21001 e conceitos relacionados à educação. Contudo no Anexo A fornece requisitos adicionais para os provedores de Educação Infantil, o que contrasta fortemente com outros padrões ISO, uma vez que os anexos dos padrões ISO servem principalmente como diretrizes para o uso. Ou seja, a ISO 21001 pretende fornecer uma ferramenta de gerenciamento comum para organizações que fornecem produtos e serviços educacionais, capazes de atender às necessidades e requisitos de alunos e outros beneficiários. Embora os principais beneficiários sejam alunos e organizações educacionais, é seguro dizer que todas as partes envolvidas podem se beneficiar de um sistema de 
gerenciamento implementado adequadamente para organizações educacionais com base na ISO 21001 e acompanhado pelas melhores práticas do setor.

Para uma instituição estar em conformidade com a norma são necessárias a realização de várias atividades obrigatórias dentro do escopo de reconhecimento do sistema de gerenciamento, ou seja, avaliações de satisfação do aluno, auditoria interna, controle de processos, revisão de programas e revisões anuais de gerenciamento dos sistemas de gerenciamento da organização, produtos ou serviços fornecidos externamente, entre outros aspectos. É importante lembrar que as normas não traçam regras de como conduzir uma empresa ou mesmo como organizá-la. Seu papel, mediante as diretrizes apresentadas em cada requisito, no conjunto que compõem cada norma, é fornecer orientações e direções para que cada empresa, de acordo com suas características e cultura, deverá seguir para implantar seu sistema da gestão.

Por se tratar de um estudo de apresentação teórica, utiliza-se a abordagem qualitativa de pesquisa, com caráter explicativo. Segundo Richardson (1999), a pesquisa qualitativa permite ao pesquisador a perspectiva de uma abordagem mais ampla e essencial relacionado ao objeto de estudo. Os dados coletados são provenientes essencialmente de fontes secundárias, sendo coletados dados secundários através de consulta das normas ISO, em revistas especializadas no campo da literatura nacional sobre o tema, livros, artigos científicos e anais de eventos.

\section{O SISTEMA DE GERENCIAMENTO PARA ORGANIZAÇÕES EDUCACIONAIS}

A ISO 21001 especifica os requisitos para um SGOE quando uma organização necessita mostrar sua capacidade de oferecer, partilhar e facilitar continuamente a concepção de conhecimento e satisfação para alunos, funcionários e clientes de acordo com os requisitos estatutários e regulamentares. A conscientização e capacitação das pessoas da organização sobre um sistema de gestão é essencial para o sucesso de sua fase de implementação. É muito importante que as pessoas tenham consciência e absorvam os onze princípios da ISO 21001 , sendo eles:

Foco nos alunos e outros beneficiários - Manter como foco principal o atendimento aos requisitos do aluno e de outros beneficiários e visando superar suas expectativas. 
Liderança visionária -É envolver todos os alunos, funcionários e outros beneficiários na elaboração, redação e implementação da missão, visão e objetivos da organização.

Engajamento de pessoas - É primordial para a organização que todas as pessoas envolvidas sejam competentes, capacitados e engajados na entrega de valores agregados ao negócio.

Abordagem de processo - Resultados consistentes e previsíveis são alcançados de maneira mais eficaz e eficiente quando as atividades são entendidas e gerenciadas como processos inter-relacionados que funcionam como um sistema coerente, incluindo entrada e saída, proporcionando maior visibilidade ao negócio.

Melhorias - As organizações de sucesso adotam uma ferramenta de melhoria contínua nos seus processos, visando buscar ininterruptamente resultados cada vez melhores.

Decisões baseadas em evidências - Decisões e currículos baseados na análise, avaliação de dados e informações têm maior probabilidade de produzir os resultados planejados.

Gerenciamento de relacionamento - Para obter sucesso sustentado, as organizações gerenciam seus relacionamentos, buscando o entendimento e antecipação das necessidades com as partes interessadas.

Responsabilidade social - Toda e qualquer ação realizada que possa contribuir para a melhoria da qualidade de vida da sociedade. As organizações socialmente e ambientalmente responsáveis são sustentáveis e garantem o sucesso a longo prazo. Ações voltadas às áreas de assistência social, saúde, fomento à educação e à moradia, cultura, dentre outros, são exemplos de responsabilidade social.

Acessibilidade e equidade - As organizações de sucesso são inclusivas, flexíveis, transparentes e responsáveis, a fim de atender às necessidades, interesses, habilidades e antecedentes individuais e especiais dos alunos e funcionários.

Conduta ética na educação - A conduta ética refere-se à capacidade da organização de criar um ambiente profissional ético, onde todas as partes interessadas são tratadas de forma equitativa, conflitos de interesses são evitados e atividades são conduzidas para o benefício da sociedade.

Segurança e proteção de dados - À medida em que as organizações embarcam na transformação digital, há uma necessidade clara de privacidade e proteção dos dados. A organização cria um ambiente em que todas as partes interessadas podem interagir com a organização educacional com total confiança de que mantêm controle sobre 0 uso de seus próprios dados e de que a organização educacional tratará seus dados com os devidos cuidados e confidencialidade. 


\section{VISÃO GERAL DA ISO 9001:2015 E DA ISO 21002:2018}

Com o uso da chamada Estrutura de Alto Nível (EAN), pode-se observar uma similaridade na ISO 9001 e na ISO 21001. A EAN é uma nova forma normalizada de elaborar as futuras normas de sistemas de gestão ISO e uma tentativa da ISO de padronizar seu próprio sistema na criação de padrões para garantir consistência em diferentes disciplinas. Elaborada em 2012 e aplicável às novas normas ISO e a revisões futuras de normas ISO existentes, os objetivos da EAN são permitir uma maior integração entre os sistemas e manter a similaridade onde todas as novas normas devem respeitar e compartilhar um núcleo consistente comum, facilitando para uma organização a aplicação de mais de um padrão ISO, como ilustrado na figura 1.

\begin{tabular}{|c|}
\hline Information (0) \\
Scope (1) \\
Terms and definitions (3) \\
Informative annexes
\end{tabular}

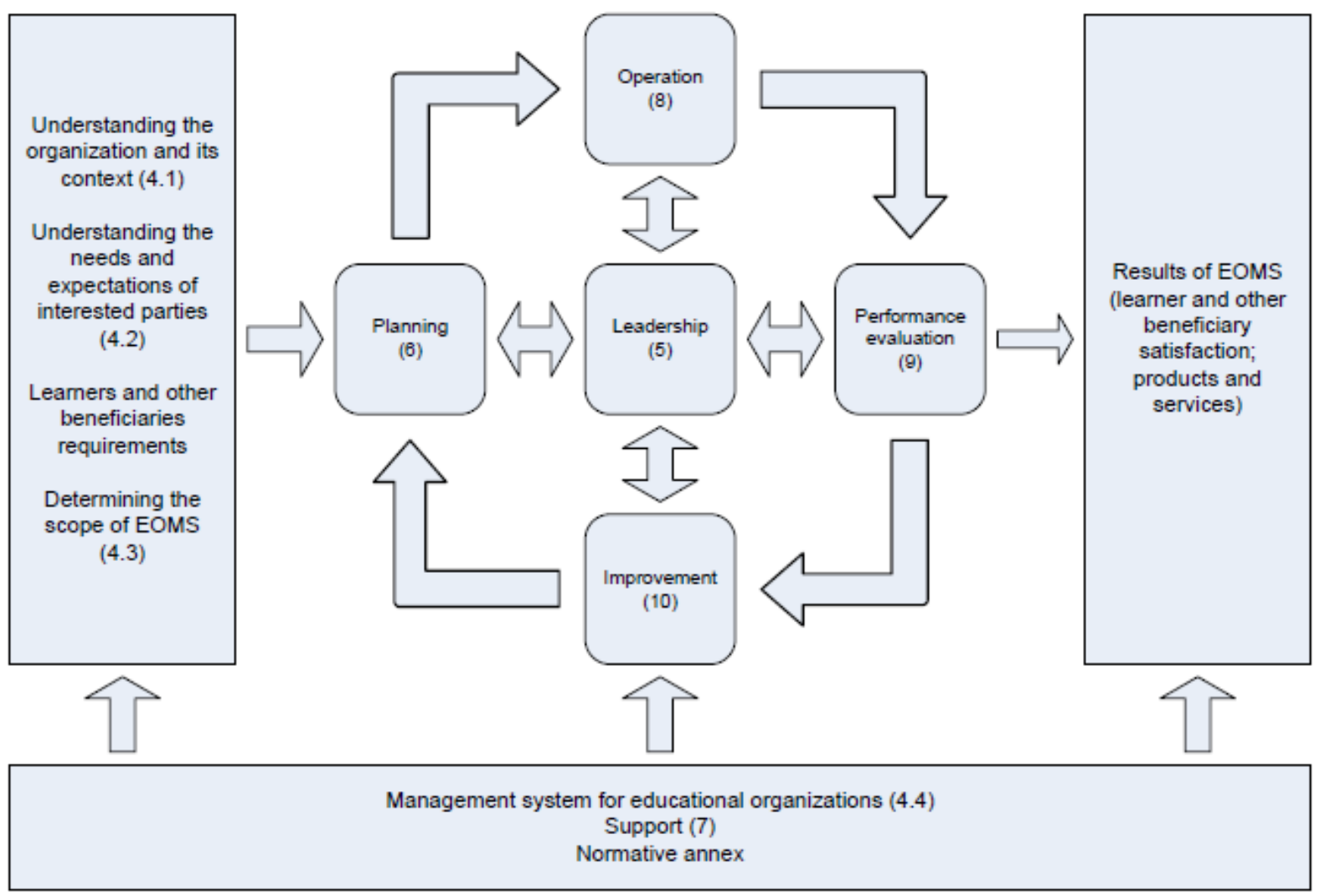




\section{FIGURA 1: Ciclo PDCA adaptado utilizado no SGOE da ISO 21001:2018 \\ Fonte: ISO21001:2018 Managementsystems for educational organizations.}

Na comparação dos princípios estabelecidos pela ISO 9001: 2015 com a ISO 21001: 2018 focamos diretamente nos princípios 4 a 10 que refletem uma sequência lógica dos requisitos dos sistemas de gestão, propondo um conteúdo comum para requisitos estabilizados dos sistemas de gestão.

Contexto da organização: Visa fazer com que toda organização tenha um entendimento completo de seus stakeholders e suas expectativas. Nota-se que não há diferenças substanciais entre os dois padrões, exceto um exemplo mais específico de partes interessadas que é dado em 21001, ou seja, alunos, beneficiários e funcionários, todavia uma parte interessada pode ocupar mais de uma posição, por exemplo um estudante de doutorado pode ser considerado tanto como estudante quanto como funcionário. Outros exemplos mais detalhados das partes interessadas são descritos no Anexo C, como segue:

- Alunos: alunos, aprendizes.

- Beneficiários: mercado de trabalho, governo, pais e responsáveis.

- Pessoal: funcionários, voluntários.

- Outros: organizações educacionais, mídia e sociedade, fornecedores externos, acionistas, parceiros comerciais, ex-alunos.

Liderança: A ISO 21001 aborda mais pontos que a ISO 9001, como alunos que necessitam de necessidades especiais e responsabilidade social. Os termos "alunos e outros beneficiários" são usados em troca de "cliente" para identificar quem são os clientes nas instituições de ensino. Também é adicionado um subtítulo abordando os requisitos para o ensino de alunos com necessidades especiais e outro subtítulo sobre 0 desenvolvimento de política com responsabilidade social e propriedade intelectual sendo levadas em consideração.

Planejamento: Neste princípio ambos os padrões apresentam pouca diferença visto que tanto 0 SGQ quanto o SGOE abordam questões de riscos e oportunidades, objetivos de organização, qualidade, planejamento para alcançá-los e o planejamento de mudanças.

Suporte: Neste princípio a ISO 21001 apresenta mais abordagem e conteúdo do que ISO 9001. Um conjunto de nove subtítulos aborda aspectos como aprendizado, engajamento e satisfação 
da equipe. $O$ subtítulo referente às instalações também é mais detalhado especificando o tipo de infraestrutura que uma organização deve fornecer e as instalações apropriadas para o ensino e aprendizagem, incluindo os espaços digitais para acomodar atividades como o aprendizado online.

Quanto ao monitoramento e medição de recursos, na ISO 21001, os requisitos ainda são gerais. Já no conhecimento da organização com relação aos recursos de aprendizagem fornecidos pela instituição, estes devem passar por revisão planejada, catalogação, referência e requisitos de propriedade intelectual. Aborda os requisitos para a educação de necessidades especiais com ênfase à avaliação de desempenho da equipe e sua melhoria contínua. Com relação a comunicação, o fato de haver muita elaboração nos requisitos de comunicação volta à questão das características dos clientes na educação, onde, diferentemente dos clientes em geral, os clientes das instituições de ensino estão ativamente envolvidos no processo de prestação de serviços e, portanto, é necessária uma comunicação intensiva entre os alunos e a instituição.

Com relação às informações documentadas são abordados os termos de proteção e segurança da informação, confidencialidade e prevenção do uso não intencional de documentos obsoletos.

Operação: Este princípio apresenta-se mais elaborado na ISO 21001 do que suas contrapartes na ISO 9001, apresentando na parte de planejamento e controle operacional, a inclusão de duas partes: (1) requisitos adicionais para educação de necessidades especiais; (2) planejamento operacional e controle específicos no projeto, desenvolvimento e resultados esperados para os resultados da aprendizagem, métodos de ensino e ambientes de aprendizagem, critérios de avaliação, avaliação da aprendizagem, métodos de melhoria e serviços de suporte.

Nos requisitos para produtos e serviços (educacionais), a ISO 21001 descreve em mais detalhes o que e como os requisitos de produtos e serviços devem ser comunicados. A fase de planejamento no design e desenvolvimento de produtos e serviços educacionais deve considerar os caminhos de aprendizado individualizados e o fornecimento de ferramentas de aprendizado. Nos controles de design e desenvolvimento, o currículo é um produto essencial que está sendo enfatizado, englobando elementos como resultados de aprendizagem, atividades, recursos e 
oportunidades. Além disso, a avaliação somativa também deve ser controlada para garantir: a) a conexão entre o desenho da avaliação e os resultados da aprendizagem a serem avaliados; b) os princípios de transparência, acessibilidade e justiça; c) definição e validação adequadas do sistema de classificação.

O processo geral nas instituições de ensino começa com a admissão, seguida pelo processo de ensino e aprendizagem, avaliação somativa e encerrada por algumas formas de reconhecimento da aprendizagem, por exemplo, anúncio do resultado dos exames, emissão do relatório de notas, etc. Há também o item que discute os requisitos adicionais para educação de necessidades especiais. A liberação de produtos e serviços (educacionais) é semelhante nos dois padrões, embora os produtos e serviços no contexto educacional sejam mais variados (livros, notas, diplomas etc.), portanto, sua liberação pode ocorrer em diferentes fases. Finalmente, no controle de produtos não-conformes tem pouca diferença quando a ISO 9001 , exige que a organização retenha informações documentadas que descrevam a entrega dos programas.

Avaliação de desempenho: Além dos requisitos gerais, a ISO 21001 exige que a organização determine os critérios de aceitação. A satisfação de alunos, outros beneficiários e funcionários (ou satisfação do cliente em 9001) é um requisito elaborado para o tratamento de reclamações e recursos, e como isso é mantido como informação documentada e divulgado às partes interessadas. Dois subtítulos extras foram adicionados na 21001 para acomodar outras necessidades de monitoramento e medição, bem como requisitos para métodos de monitoramento, medição, análise e avaliação, vinculadas ao Anexo E. Para a análise e avaliação, a ISO 21001 exige a inclusão de satisfação dos beneficiários e funcionários. 0 subtítulo de auditoria interna é diferente apenas na parte em que, na ISO 21001, oportunidades de melhoria devem ser identificadas. Da mesma forma, o subtítulo de revisão gerencial não é muito diferente, apenas que, na ISO 21001, os resultados da avaliação formativa e o feedback da equipe devem ser considerados como parte das entradas da revisão gerencial.

Melhoria: Ambas as normas têm requisitos idênticos nesta cláusula, seguindo o foco em aumentar a importância lógica das iniciativas de melhoria, em que a correção precisa ser executada imediatamente caso ocorram não-conformidades, seguidas de melhoria contínua e identificação adicional de oportunidades de melhoria 


\section{A ADOÇÃO DO PDCA NOS SISTEMAS DE GESTÃO}

A partir da década de 50 do século anterior, aumentou-se a ênfase com a preocupação na gestão da qualidade, trazendo um novo pensamento gerencial com base na aplicação e desenvolvimento de métodos, conceitos e técnicas propícias a uma nova forma de organização produtiva. Essa nova filosofia de organização ficou conhecida como "Gestão da Qualidade Total" e marcou a transição da análise do serviço ou produto para a formulação de um sistema de gestão da qualidade. A qualidade deixou de ser uma característica do produto e incumbência apenas de departamento representativo, e passou a ser um problema geral da empresa, incluindo toda concepção de operação e produção com o propósito de garantir que seus produtos e seus distintos processos atendam às necessidades dos usuários, as expectativas dos clientes internos e externos é implantado o Sistema de Gestão da Qualidade.

O ciclo PDCA (Plan, Do, Check, Act) é uma ferramenta gerencial de planejamento para facilitar a tomada de decisões e garantir o cumprimento das ações necessárias à continuidade de uma organização, sendo muito utilizado no cumprimento da gestão de qualidade total (TQM). O norte americano Walter Andrew Shewhart desenvolveu o ciclo Specify-Product-Inspect (Especificar-Fazer-Inspecionar), conceito primordial da gestão da qualidade, contudo William Edwards Deming implantou a metodologia no Japão após a II Guerra Mundial, adicionando mais uma parte ao ciclo de Shewhart. Desta forma, o PDCA ficou popularmente conhecido como Ciclo de Deming. De acordo com MARANHÃO (2002), o ciclo pode ser demonstrado como na Figura 2. 


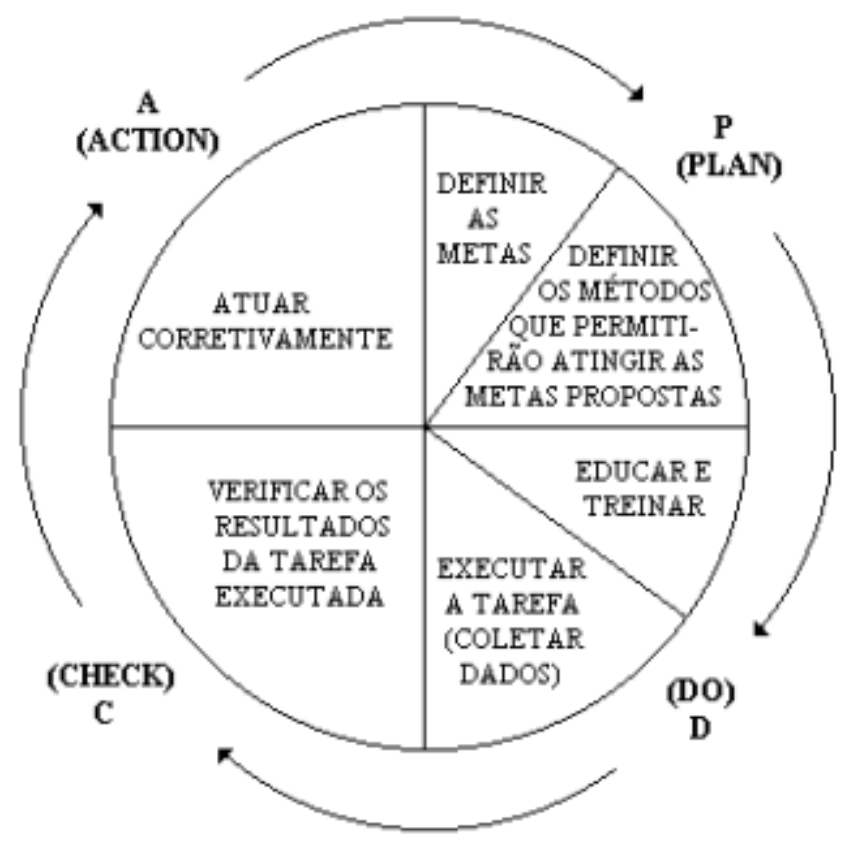

FIGURA 2 - Detalhamento do Ciclo PDCA

Fonte: MARANHÃO (2002)

P (Plan) - Planejar as ações a serem realizadas;

$D(D o)$ - Executar as ações planejadas;

C (Check) - Avaliar ou medir o que foi realizado, visando identificando a diferença entre o que foi feito contra o que foi planejado;

A (Action) - Atuar corretivamente sobre a diferença identificada. A atuação corretiva pode ser aplicada sobre o que foi realizado (retrabalho, reparo, etc.) ou sobre o que foi planejamento.

De acordo com a NBR ISO 9001:2008 o modelo PDCA pode ser assim resumido:

Plan (planejar): estabelecer os objetivos e os processos necessários para gerar resultados de acordo com os requisitos do cliente e com as políticas da organização.

Do (fazer): implantar os processos.

Check (checar): monitorar e medir processos e produtos em relação às políticas, aos objetivos e aos requisitos para os produtos e relatar os resultados.

Act (agir): executar ações para promover continuamente a melhoria do desempenho do processo.

Ainda de acordo com esta norma, o sistema de gestão da qualidade é um sistema de melhoria contínua, no qual as necessidades dos clientes são atendidas na produção. A melhoria contínua 
só é possível com a mobilização de recursos, com a responsabilidade da direção e com a medição, análise e melhoria do processo construtivo. 0 método foi originalmente proposto para realizar o controle estatístico do processo, mas pode ser perfeitamente aplicado em processo de gestão, para garantir sua efetividade, inclusive na identificação dos erros e na investigação das causas e na sua eliminação. Após a elaboração de padrões e da documentação do Sistema da Qualidade, a sua implantação deve ser feita de acordo com o ciclo PDCA.

Pode-se observar que é um instrumento importante a gestão dos processos e implantação de melhorias, sendo primordial que os funcionários saibam utilizá-la. O ciclo PDCA aborda os princípios da administração constituindo-se de uma forma simples e de fácil entendimento, possibilitando seu uso pelas organizações. Os processos precisam ser realizados conforme os padrões e devem ser controlados, possibilitando a verificação dos resultados e a sua conformidade aos padrões definidos. Os processos possuem seus respectivos indicadores e padrões de controle de qualidade pré-estabelecidos pela política da empresa.

As ações corretivas são implantadas em caso de identificação de não-conformidade visando, inicialmente, consertar a falha e posteriormente identificar ao longo do processo as causas da não conformidade, e assim implantadas as ações necessárias para evitar as repetições. Conclui-se assim o ciclo PDCA, revisando as documentações e o padrão da qualidade, permitindo as alterações e revisões corretivas nos documentos. Com a aplicação ciclo PDCA promove-se uma otimização dos processos com o aumento da produtividade, redução de custos e elimina-se o desperdício por retrabalho.

O emprego do PDCA e o cumprimento de ações preventivas e corretivas promovem a melhoria contínua da empresa possibilitando a consolidação e fortalecimento do Sistema de Gestão da Qualidade. O ciclo propõe que a organização de melhorias se inicia com um planejamento detalhado com foco na definição da meta, resultando em uma ação eficaz de correção ou implantação e deve retornar novamente ao planejamento em um ciclo contínuo. Conforme o conceito de melhoria contínua, o processo sempre pode ser analisado novamente e uma nova ação de mudança poderá ser iniciado.

A utilização do Ciclo PDCA não se limita a alta gerência e diretoria, mas também se aproxima mais da equipe operacional com o foco de alinhar e somar os empenhos de melhoria contínua. A organizações possuem resultados e objetivos que planejam manter e outros que planejam melhorar, sendo possível a aplicação do método PDCA nestes dois casos. Na opinião de FALCONI (2009), qualquer resultado que se melhora deve, imediatamente, ser estabilizado nas operações do dia a dia por meio da padronização e do treinamento no trabalho. O PDCA 
utilizado para manter é conhecido como SDCA, onde o S (Standardize) que significa uniformizar e substitui o P (Plan).

Ao fim da implantação de um Sistema de Gestão da Gerenciamento da Organização Educacional que cumpra as exigências básicas necessárias de uma norma, a empresa pode solicitar uma certificação. Essa certificação resume-se em contratar um órgão certificador independente credenciado pelo INMETRO (Instituto de Normalização, Metrologia e Qualidade Industrial) e através das auditorias realizadas no sistema de gestão da organização, certifica-se se esta cumpre os itens da norma e estes estão implantados de acordo com os requisitos básicos. No Brasil há diversas empreses certificadoras empreendendo no mercado, sendo grande parte de origem estrangeira.

\section{CONSIDERAÇÕES FINAIS}

No desenvolvimento deste artigo discutiu-se o sistema de gerenciamento de organização educacional recentemente publicado da ISO, denominado ISO 21001: 2018. A discussão gira em torno da comparação entre este SGOE e o SGQ ISO 9001: 2015 mais popular. A justificativa para a necessidade de um padrão específico para organizações educacionais também foi discutida e fundamentada na revisão da literatura.

Usando a análise qualitativa comparando diretamente os dois padrões, foi obtida a seguinte conclusão. Primeiro, os dois padrões usam a mesma estrutura chamada Estrutura de Alto Nível, que compreende as mesmas cláusulas de 1 a 10. Isso permite a comparação direta entre os dois. Em segundo lugar, sendo distintamente adaptado para a educação, vários termos usados na ISO 21001 são muito específicos, principalmente a adoção das palavras "aluno" (incluindo "outros beneficiários") para "cliente" e "currículo" e "cursos" e seus atributos associados, como resultados de aprendizagem, avaliação, notas etc. para "produtos".

A norma também reconhece que os clientes da educação, diferentemente dos das empresas regulares, estão ativamente envolvidos no processo, exigindo que seja estabelecida uma comunicação mais intensa entre a instituição como prestadora de serviços e seus alunos. Em terceiro lugar, o escopo da ISO 21001 é mais amplo e profundo do que o da ISO 9001, como pode ser visto nos subtítulos adicionais. Por fim, a educação para necessidades especiais é enfatizada, pois é mencionada frequentemente em todo o padrão. 
A partir da conclusão acima, argumentamos que as organizações educacionais podem adotar a ISO 21001 para seu sistema de gestão em vez da ISO 9001. A questão permanece se a nova norma será preferida à ISO 9001, mais amplamente aceita, em vista do benefício mercadológico. Até o momento, nenhum estudo de caso foi encontrado sobre a implementação da ISO 21001 no Brasil, o que em certa medida também limita este estudo.

Em síntese, com o advento de tais estudos de caso no futuro e depois que o novo padrão atingir seu estágio de maturidade, esse poderá ser um caminho de pesquisa viável, face à situação extremamente complexa da escola neste tempo de pandemia da COVID-19, considerando principalmente as dimensões da qualidade envolvidas no processo de gestão e da avaliação da organização escolar, pela sua importância social e política, diante das inúmeras questões contemporâneas que desafiam os gestores. Eis aqui um ponto de partida, não de chegada.

\section{REFERÊNCIAS}

ABNT - ASSOCIAÇÃO BRASILEIRA DE NORMAS TÉCNICAS. ABNT NBR 15419 Sistema de gestão da qualidade: diretrizes para aplicação da ABNT NBR ISO 9001:2000 nas organizações educacionais. Rio de Janeiro: ABNT, 2006.

ABNT - ASSOCIAÇÃO BRASILEIRA DE NORMAS TÉCNICAS. NBR/ISO 9001:2008 Sistema de gestão da qualidade: Requisitos. Rio de Janeiro: ABNT, 2008.

ABNT - ASSOCIAÇÃO BRASILEIRA DE NORMAS TÉCNICAS. NBR/ISO 9001:2015 Sistema de gestão da qualidade: Requisitos. Rio de Janeiro: ABNT, 2015.

BRESSER-PEREIRA, Luiz Carlos. Reforma do Estado nos anos 90: lógica e mecanismos de controle. Brasília: MARE, Cadernos MARE, n. 1, 1997. Disponível em< http://www.scielo.br/pdf/ln/n45/a04n45.pdf >. Acesso em: 25 mar 2020.

CABRAL NETO, Antônio; CASTRO, Alda Maria Duarte Araújo. Gestão escolar em instituições de Ensino Médio: entre a gestão democrática e a gerencial. Revista Educação e Sociedade. Campinas, v. 32, n. 116, p. 745-770, jul.-set.2011.

CÁRIA, Neide Pena. OLIVEIRA, Sandra Maria da Silva Sales e CUNHA, Neide de Brito. (Orgs.). Gestão educacional e avaliação: perspectivas e desafios contemporâneos. Campinas: Pontes, 2015

FALCONI, Vicente, O Verdadeiro Poder, Nova Lima - MG: INDG Tecnologia e Serviços Ltda, 2009.

ISO 21001: 2018. Educational organizations - management systems for educational organizations - requirements with guidance for use. 
LIMA. Licínio Carlos. A escola como organização educativa. São Paulo: Cortez, 2011.

LIMA, Licínio Carlos. Educação ao Longo da Vida: entre a mão direita e esquerda de Miró. São Paulo: Cortez, 2007.

MARANHÃO, Mauriti. ISO série 9000: manual de implementação. 6. ed. Rio de Janeiro: Qualitymark, 2001.

RICHARDSON, Roberto Jarry. Pesquisa Social: métodos e técnicas. São Paulo: Atlas, 1999. 